\title{
SOCIETY FOR THE STUDY OF FERTILITY
}

\section{ANNUAL CONFERENCE}

T HE annual conference of the Society for the Study of Fertility was held in the Meeting House of the Zoological Society of London during July 22-23, when the opportunity was also taken to celebrate the fifth anniversary of the Society's existence. The proceedings opened with a paper by R. Irving-Bell on the routine clinical examinations carried out at the Male Subfertility Clinic at Bristol, followed by a group of three papers from the Department of Anatomy, Liverpool, by Prof. R. G. Harrison and his colleagues, on some fundamental aspects of the structure and function of the rat testis and the male accessory organs. In the first paper, concerned with the influence of freezing temperatures on the rat testis, Prof. Harrison and Miss Jean Macdonald elaborated in detail their thesis that the adverse effects of low temperatures on spermatogenesis are due directly to ischæmia. Next, E. W. Macmillan gave an account of his experiments on the anatomical factors in the male which determine the normal rate of disposal and dissolution of epididymal spermatozoa, and which predispose to the formation of spermatocoele. E. J. Clegg described the response of rat accessory glands to the interruption of arterial blood supply. His finding that, when deprived of the normal blood supply, the coagulating glands cease to secrete fructose is a good indication that the blood-flow in the accessory reproductive organs is of decisive significance for composition of the seminal plasma.

Dr. Cecilia Lutwak-Mann (Cambridge) spoke next on the physiology and biochemistry of the nearimplantation stages of pregnancy in the rabbit. She has found that very little glucose is present in the young unattached blastocyst (six days after fertilization), but that the content of this sugar begins to increase markedly as implantation progresses. This is in contrast to the content of bicarbonate ions, which in the unimplanted blastocyst are almost three times more concentrated than in the maternal blood but which decrease to maternal serum-level after the implantation. The remarkably high content of bicarbonate in the free-lying blastocyst coincides with the appearance in the mucosa of the pregnant uterus of carbonic anhydrase, the zinc-protein enzyme which is well known to be concerned with bicarbonate metabolism in the animal body. From Dr. LutwakMann's experiments concerning the passage of a variety of substances from the maternal blood stream into the blastocyst, it appears that, so long as the blastocyst remains free in the uterus, it is largely independent of major changes in the maternal blood composition. Once implantation is completed, several substances, including certain drugs, are capable of passing freely from the maternal blood into the blastocyst cavity.

This paper was followed by a group of three reports, all of them concerned with different clinical aspects of human infertility: D. M. Shotton (Birmingham) spoke on the obstetric management of infertile women, M. C. N. Jackson (Exeter) presented her records on the follow-up of infertility cases, extending over many years of observation, and Dr. $J$. Loewenstein (London) described in detail the use of mechanotherapy in subfertile men.

The session on the next day opened with a paper by Dr. E. J. Farris (Philadelphia) on the value of ovulation timing in the sterile couple, followed by two other guest-speakers from abroad: Dr. G. E. Seegar Jones (Baltimore), who discussed the relationship between adrenal hyperplasia and fertility, and Dr. Raoul Palmer (Paris), describing the use of coeliscopy in the diagnosis of reproductive disorders in women. The remaining papers centred largely on the problem of male sterility and sperm physiology and biochemistry. Dr. G. I. M. Swyer (London) commented eritically on the value of testicular biopsy as a clinical procedure. Dr. A. S. Parkes and Dr. P. Spensley, from the National Institute for Medical Research, Mill Hill, reported on their experiments with 'Rehibin', a condensation product of gentisic acid, and on certain other new macromolecular polyacids in relation to their action on hyaluronidase and the fertilizing capacity of rabbit spermatozoa. An interesting fact brought to light by these researches was that, in spite of the marked inhibitory effect on sperm-hyaluronidase which coincided with a decrease in fertilizing capacity, 'Rehibin' and similar polyhydroxybenzoic acid condensation products are not necessarily spermicidal agents-for example, they do not deprive the spermatozoa of their motility and metabolic activity.

Metabolic processes in spermatozoa and their relation to the so-called dilution effect were dealt with by Dr. M. W. H. Bishop (Cambridge), who reported also on the use of a new glycine-containing artificial medium in the practice of semen preserva. tion. He was followed by Dr. T. Mann (Cambridge), who spoke on the biochemical mechanisms underlying the action of spermicidal agents, and on his recent investigations which make it possible to distinguish clearly three groups of spermicidal substances : enzymic inhibitors, which act directly upon certain intermediary reactions in sperm respiration and fructolysis ; sulphydryl-binding substances which combine with the vital thio-groups in spermatozoa; and surface-active substances which owe their spermicidal property to a detergent action on lipoprotein and other protein-constituents of the spermcell.

As in previous years, the papers presented at the Conference will be published by W. Heffer and Sons, Ltd., Cambridge, as a separate volume (No. 6) of the Proceedings of the Society for the Study of Fertility.

\section{METEOROLOGY AND SCOTTISH AGRICULTURE}

TWO symposia were held by the Royal Meteorological Society as part of its summer meeting during July 15-17 in the Natural Philosophy Depart. ment of the University of Edinburgh. The first was on "The Upper Atmosphere" (see Nature, August 21, p. 334), and the second, which was held on July 17, was devoted to "Meteorology and Scottish Agriculture". The first speaker at this latter symposium was Dr. John Grainger (West of Scotland Agricultural College, Auchincruive), who suggested, by graded examples, that studies on relationships between climate and crop diseases should consider effects on the host plant, in addition to those on the parasite. 